\title{
Contributions of Thinking Styles to Critical Thinking Dispositions
}

\author{
LI-FANG ZHANG \\ Faculty of Education \\ The University of Hong Kong
}

\begin{abstract}
The main purpose of the author's research was to investigate whether thinking styles significantly contribute to critical thinking dispositions. Two samples of Chinese university students, one from Beijing and the other from Nanjing, participated in the study. The participants responded to the Thinking Styles Inventory (R. J. Sternberg \& R. K. Wagner, 1992) based on Sternberg's theory of mental self-government and to the California Critical Thinking Disposition Inventory (P. Facione \& N. Facione, 1992). which assessed the 7 dimensions of the critical thinking construct as defined in The Delphi Report (see P. Facione, N. Facione, \& C. Giancarlo, 2001). Results from both samples supported the prediction that thinking styles statistically contribute to individual differences in crifical thinking dispositions. These findings have implications not only for classroom instruction and assessment but also for academic and nonacademic program development.
\end{abstract}

Key words: critical thinking dispositions, thinking styles

THE SUCCESS OF AN ACADEMIC PROGRAM depends on many vital characteristics. Among them, two stand out - a good academic program (a) facilitates critical thinking and (b) recognizes a variety of intellectual styles (e.g., Lefton, 1997: Marra, 1997). In literature, each of these areas has been examined extensively. However, few researchers have investigated the relationships between the two constructs. In the present study, I examined the contributions of thinking styles as defined by Sternberg's $(1988,1997)$ theory of mental self-government to the critical thinking dispositions as defined by the cross-disciplinary panel for the 2-year Delphi project completed in 1990 under the sponsorship of the American Philosophical Association (see Facione, Facione, \& Giancarlo, 2001).

I am grateful to the Committee on Research and Conference Grants, administered by The University of Hong Kong, for supporting this research. My sincere thanks go to Liti Zhang for her great help with the data collection.

Address correspondence to Li-fang Zhang, Faculty of Education. The University of Hong Kong, Pokfulam Road, Hong Kong. Ifzhang@hkucc.hku.hk (e-mail). 
Sternberg's (1988, 1997) theory of mental self-government is one of the many theories of intellectual styles. The term intellectual style is used here to refer to the constellation of the various labels with the root word style. The three most frequently used are cognitive style, learning style, and thinking style. Although these three may be viewed as overlapping historically, they have been conceptualized in somewhat different ways. Cognitive styles might be used to describe how one cognizes information. Learning styles might be used to illustrate how one prefers to learn about certain information. Finally, thinking styles might be used to characterize how one prefers to think about the information as one is learning it or after one already knows it.

Theories of styles flourished between the late 1950s and early 1970s. However, the seemingly permanent research on and theorization of styles subsided partially because of the overwhelming output from the field and partially because of its lack of internal dialogue among scholars in the field (Jones, 1997).

In the past decade or so, there has been renewed interest in the study of styles represented by two types of effort. One is to make conceptual integration. The other is to conduct empirical studies (see Zhang, 2000a, for details). Among the efforts in conceptual integration, four of the integrated models are the most promising. The first is Curry"s (1983) three-layer "onion" model. The second is Miller's (1987) model of cognitive processing and styles. The third is Riding and Cheema's (1991) model of two style dimensions and one family of learning strategies. The final and most recent integrated model is that by Sternberg (1997). The theoretical foundation for the present study is Sternberg's integrated model of works on styles.

Sternberg (1997) proposed that works on styles fall into one of the three traditions: cognition centered, personality centered, and activity centered. Styles in the cognition-centered tradition most closely resemble abilities. Moreover, like abilities, styles in this tradition are measured by tests of maximal performance with "right" and "wrong" answers. Within this tradition, two models of styles have aroused the most interest: Witkin's (1964) field-dependence/independence model and Kagan's (1976) reflection-impulsivity model.

The personality-centered tradition considers styles as most closely resembling personality traits. Furthermore, like personality traits, styles in this tradition are measured by tests of typical, rather than maximal, performance. Major work in this tradition has been done by Myers and McCaulley (1988) based on Jung's (1923) theory of personality types. Holland's $(1973,1994)$ theory of vocational types and Gregorc's (1979) model of types of styles also fall into this tradition.

The activity-centered tradition focuses on the notion of styles as mediators of various forms of activities that tend to arise from aspects of both cognition and personality. One major group of works in this tradition is represented by similar theories of deep- and surface-learning approaches proposed by Marton (1976), Biggs (1978), Entwistle (1981), and Schmeck (1983). Moreover, Renzulli and Smith (1978) proposed different learning styles, each corresponding to a method of teaching such as discussion, drill and recitation, or lecturing. 
The style constructs proposed by theorists from the three traditions, although different, have one key common characteristic. That is, all style constructs are different from abilities. Whereas abilities refer to what we can do, styles refer to our preferred ways of using the abilities that we have.

The year 1988 saw the publication of Sternberg's theory of styles: the theory of mental self-government (see also Sternberg, 1997). Using the word "government" as the metaphor, Sternberg contended that just as there are many ways of governing a society, there are many ways of managing our activities. These different ways of managing our activities are what Sternberg termed thinking styles. In managing our activities, we choose to use thinking styles with which we feel comfortable. Moreover, styles are not "good" or "bad" in themselves; but rather, the utility of a style is time- and task-dependent. Finally, thinking styles are at least partially socialized and thus can be modified.

The theory depicts 13 thinking styles that fall along 5 dimensions. These are three functions (legislative, executive, and judicial styles), four forms (hierarchical, oligarchic, monarchic, and anarchic styles), two levels (global and local styles), two scopes (internal and external styles), and two leanings (liberal and conservative styles) of mental self-government. Each of these 13 thinking styles is briefly summarized in Appendix A.

Although thinking styles are not good or bad, as argued by Sternberg, research has shown that the majority of the thinking styles in Sternberg's theory can be classified inte two groups (e.g., Zhang, 2000a, 2000b, 2001b, 2001c, 2002b, 2002d; Zhang \& Huang, 2001; Zhang \& Postiglione, 2001; Zhang \& Sternberg, 2000). The first group consists of thinking styles that generate creativity and require higher levels of cognitive complexity, including the legislative, judicial, hierarchical, global, and liberal styles (referred to as Type 1 thinking styles hereafter). The second group contains thinking styles that denote a norm-conforming tendency and that require lower levels of cognitive complexity; these include the executive, local, monarchic, and conservative thinking styles (referred to as Type 2 thinking styles hereafter).

The remaining four thinking styles (anarchic, oligarchic, internal, and external) may be perceived as belonging neither to the Type 1 group nor to the Type 2 group. However, they may manifest the characteristics of the styles from both groups, depending on the stylistic demand of the specific task. For example, whether one prefers to work alone (internal style) or one prefers to work with others (external style), one can work on tasks that require either Type 1 or Type 2 thinking styles. Also for instance, one could use the anarchic style in a sophisticated way, such as dealing with different tasks as they arise but without losing the whole picture of what one wants to achieve. Under this circumstance, the anarchic style manifests the characteristics of Type 1 thinking styles.

$\mathrm{Or}$ on the contrary, one could also use the anarchic style in a simple-minded way, such as dealing with tasks as they come along without knowing how each task contributes to the ultimate goal. Under this circumstance, the anarchic style mani- 
fests the characteristics of Type 2 thinking styles. These four thinking styles (anarchic, oligarchic, internal, and external) have not been explicitly labeled in previous studies. In the present study, these styles are referred to as Type 3 thinking styles.

The theory of mental self-government is a general theory of styles. I make this assertion not only because the theory applies to both the academic and nonacademic settings but also because it embraces all three traditions to the study of intellectual styles. The thinking styles in this theory are cognitive in their way of looking at things (e.g., judicial style, global style, and so forth) and correspond to preferences in the use of abilities. However, the styles are assessed by typical performance, not maximal performance. Thus, they resemble the personalitycentered tradition. Finally, the styles resemble the activity-centered tradition in that they can be measured in the context of specific activities.

The theory of mental self-government has been tested by a few instruments, including by the most frequently employed Thinking Styles Inventory (Sternberg \& Wagner, 1992). The internal validity of the inventory has been obtained in many studies (e.g., Bernardo, Zhang, \& Callueng, 2002; Dai \& Feldhusen, 1999; Zhang, 1999, 2001c; Zhang \& Sternberg, 1998) conducted among students and teachers from a number of cultural groups and countries, including Hong Kong, mainland China, the Philippines, and the United States.

Furthermore, a continuous effort has been attempted to test the nature of thinking styles. Thinking styles have been tested not only against a number of constructs that belong to the family of styles. but also against a few variables that are believed to be significantly related to thinking styles. For example, pertaining to the former, thinking styles have been tested against the learning approaches defined by Biggs (1978, 1992), the vocational interest and personality types proposed by Holland (1973, 1994), and the styles of thinking and learning proposed by Torrance, McCarthy, and Kolesinski (1988). Regarding the latter, thinking styles have been tested against the self-esteem construct proposed by Coopersmith (1981), the cognitive development construct as defined by Perry $(1970,1981,1999)$, the Big Five personality traits (Costa \& McCrae, 1992), and psychosocial development as represented by the development of purposefulness in three aspects: vocational, avocational, and style of life (Chickering, 1969; Chickering \& Reisser, 1993).

Detailed findings about the relationships of thinking styles to each of the variables examined can be identified in their respective original studies (e.g. Zhang, 2001b, 2002a, 2002b, 2002c, 2002d; Zhang \& Huang, 2001; Zhang \& Postiglione, 200I; Zhang \& Sternberg, 2000). Let it suffice to say here that these studies have indicated that Type 1 thinking styles were significantly correlated with human attributes that are usually believed to be positive (e.g., high selfesteem, a deep approach to learning, a high cognitive development level, and the personality trait of openness). Type 2 thinking styles were significantly related to human attributes that are usually viewed as being negative (e.g., low self-esteem, a surface approach to learning, a low cognitive development level, and the personality trait of neuroticism). 
In this research I have suggested that the thinking style construct plays an important role in a number of aspects pertaining to student development both inside and outside the classroom. These aspects include students' affective, cognitive, and psychosocial development. However, the contribution of thinking styles to critical thinking has yet to be investigated.

Critical thinking is a general term that is often used to refer to two related and yet very different concepts - ability and disposition. The former refers to one's ability to think critically, whereas the latter refers to one's propensity for thinking critically.

In literature, research on the relationships between intellectual styles and critical thinking is barely documented. A thorough search of the PsycInfo database using different combinations of the key words "critical thinking, critical thinking disposition, learning styles, cognitive styles, and thinking styles" resulted in only eight works, of which seven are empirical research. Findings of these empirical studies are mixed. For example, whereas Mcdade's (2000) study of health professional students found significant relationships of the intuition learning style to the inquisitiveness and truth-seeking dispositions as well as to the total critical thinking disposition score (see also Bostic. 1989; Gadzella \& Masten, 1998; Marra, 1997), Nathan's (1997) study of nursing students identified no significant relationship between the Watson-Glaser Critical Thinking Appraisal (Watson \& Glaser, 1980) and Kolb's (1976) Learning Style Inventory (see also Krank, 1994; Mccrink, 1999). The studies that found significant relationships between intellectual styles and critical thinking supported the argument that intellectual styles play an important role in critical thinking. Furthermore, results of the nonempirical work done by Feldhusen and Goh (1995) argued that critical thinking is an integral part to the concept of creativity and that programs with the aim of promoting creative thinking must focus on cognitive styles among other factors.

In the present study 1 investigated contributions of the thinking styles as defined by the theory of mental self-government to the critical thinking dispositions as defined by the cross-disciplinary panel for the 2-year Delphi project sponsored by the American Philosophical Association and completed in 1990 (see Facione et al., 2001).

In the California Critical Thinking Disposition Inventory manual (Facione et al., 2001), the consensus statement reached in The Delphi Report was reproduced:

The ideal critical thinker is habitually inquisitive, well-informed, trustful of reason, open-minded, flexible, fair-minded in evaluation, honest in facing personal biases, prudent in making judgments, willing to reconsider, clear about issues, orderly in complex matters, diligent in seeking relevant information, reasonable in the selection of criteria, focused in inquiry, and persistent in seeking results which are as precise as the subject and the circumstances of inquiry permit. (p. 1)

According to this expert consensus, there are seven dimensions to the critical thinking disposition construct. The first dimension is truth seeking. Truth seekers 
are honest and objective about pursuing inquiry even if their interests or perceived opinions are not supported by the findings. They are willing to reconsider and revise their views when honest reflection suggests that change is needed.

The second dimension is open-mindedness. Open-minded people are tolerant of divergent views and sensitive to the possibility of their own bias. The primary concern of open-minded people is to acknowledge the rights of others to hold their opinions. The third dimension is analyticity. Analytically inclined people are alert to potential difficulties and are constantly looking for solutions to problems. They are alert to and evaluative of the outcomes. The fourth dimension is systematicity, Systematic people are characterized by orderliness in working with complexity. They strive to approach specific issues, problems, or questions in an orderly, focused, and diligent way, no matter how that might be accomplished.

The fifth dimension is critical thinking (CT) self-confidence. CT self-confident individuals place a high level of trust in their ability to reason. They trust themselves to make good judgments and believe that others look to them to resolve problems. The sixth dimension is inquisitiveness. Inquisitive people are intellectually curious. They value being well informed and want to learn how things work even if the immediate payoff is not directly evident. The last dimension is maturity. Mature people make reflective judgments. They are cognitively more developed and are disposed to approach problems with the understanding that some problems are ill-structured, some situations admit of more than one option, and that many times there are no definite answers to questions.

In the present study I chose to test the contributions of thinking styles to critical thinking dispositions rather than to critical thinking ability. There are two major similarities between thinking styles and critical thinking dispositions, First, as defined earlier, a thinking style refers to the preferred way of using abilities. Likewise, a critical thinking disposition refers to the tendency for thinking critically. Thus, underlying both constructs is the notion of a human being's thinking habits (habits of the mind).

Second, both thinking styles and critical thinking dispositions are broad constructs in their own ways. Whereas the thinking style construct embraces the characteristics of styles from all three traditions to the study of intellectual styles, as mentioned earlier, the critical thinking disposition construct is claimed to be "discipline neutral and comprises a generalizable description of the ideal critical thinker across multiple contexts and situations" (Facione et al., 2001, p. 2).

I predicted that thinking styles would significantly contribute to critical thinking disposition, first, on the basis of significant findings in previous research on the relationships between intellectual styles and critical thinking, and second, because of the similarities between the two constructs, as discussed earlier.

As mentioned, previous research has shown that Type 1 thinking styles tend to be related to a variety of attributes that are normally perceived to be more positive, such as a deep approach to learning, higher self-esteem, higher cognitive developmental levels, and the openness personality trait. Type 2 thinking styles 
tend to be related to attributes that are normally perceived to be more negative, including a surface approach to learning, lower self-esteem, lower cognitive developmental levels, and the neuroticism personality trait. Critical thinking dispositions are regarded as positive attributes.

I made the following predictions between the three types of thinking styles and the critical thinking dispositions. First, Type I thinking styles would significantly contribute to critical thinking dispositions in a positive way. Second, Type 2 thinking styles would significantly contribute to critical thinking dispositions in a negative way. Third, Type 3 thinking styles would significantly contribute to critical thinking dispositions in either a positive or a negative way, or in both ways.

I made no specific predictions regarding how each of the thinking styles would contribute to each particular critical thinking disposition because all seven critical thinking dispositions are perceived as being positive attributes with the underlying notion of reasoned inquiry. Therefore, the specific thinking styles from which each of the seven critical thinking dispositions take effect may be quite similar.

\section{Method}

\section{Participants}

Participants were two samples of university students from mainland China. The first was composed of 268 (69 men and 199 women) students from a comprehensive research-oriented university in Beijing whose ages ranged from 17 to 24 years ( 19 years was both the mean and the median). There were 94 freshmen, 83 sophomores, 56 juniors, and 35 seniors working toward their bachelor's degrees in the areas of biology, education, management, philosophy, and physics.

The second sample consisted of 296 (143 men and 153 women) students from a large teacher's training university in Nanjing whose ages ranged from 16 to 23 years (average age was 20 years). There were 120 freshmen, 80 sophomores, 76 juniors, and 20 seniors working toward their bachelor's degrees in the areas of biology, Chinese language, computer science, education, international trade, and physics.

\section{Measures}

All participants responded to the Thinking Styles Inventory (TSI, Sternberg \& Wagner, 1992) and the California Critical Thinking Disposition Inventory (CCTDI, Facione \& Facione, 1992). The TSI is based on Sternberg's theory of mental self-government, and the CCTDI is based on the aforementioned expert consensus on the essential characteristics of an ideal critical thinker.

The Thinking Styles Inventory contains 65 statements; each group of 5 statements assesses one of the 13 thinking styles described in the theory of mental self-government. Each statement is rated on a 7-point Likert-type scale ranging 
from 1 to $7: 1$ indicates that the statement does not at all describe the way one tends to carry out his or her tasks and 7 indicates that the statement characterizes extremely well the way one tends to carry out tasks. In the present study, the participants responded to the Chinese version of the inventory that had been translated and back-translated between Chinese and English in 1996.

As mentioned earlier, both the English and Chinese versions of the inventory have obtained good reliability data as well as sound internal and external validity. The Cronbach alpha coefficients have normally ranged from the low .50 s to the low $.80 \mathrm{~s}$. In the present study, the Cronbach alpha coefficients for the Beijing sample were $.75, .63, .71, .66, .51, .84, .73, .77, .48, .71, .50, .79$, and .75 , respectively, for the legislative, executive, judicial, global, local, liberal, conservative, hierarchical, monarchic, oligarchic, anarchic, internal, and external thinking styles. For the Nanjing sample, the Cronbach alpha coefficients were .69, .63. $.70, .59, .52, .87, .75, .70, .50, .73, .51, .74$, and .76 , respectively, for the legislative, executive, judicial, global, local, liberal, conservative, hierarchical, monarchic, oligarchic, anarchic, internal, and external thinking styles.

The validity of the TSI in the present study was consistent with what has been obtained in previous studies on thinking styles. I obtained a four-factor model for both sets of data. Moreover, the scales clustered in the same fashion in the two data sets. That is, in both data sets, the first factor was dominated by Type 1 thinking styles, whereas the second factor was dominated by Type 2 thinking styles. Furthermore, in both data sets, the third factor showed high loadings that contrasted the internal and external styles, and the fourth factor showed high loadings that contrasted the global and local styles. Finally, the four factors accounted for $67.16 \%$ of the variance in the Beijing data and $64,69 \%$ of the variance in the Nanjing data.

The CCTDI consists of 75 statements falling into 7 scales (i.e., Truth Seeking, Open-Mindedness, Analyticity, Systematicity, CT Self-Confidence, Inquisitiveness, and Maturity), each assessing one of the seven dimensions of the critical thinking disposition construct. The seven scales of the CCTDI include from 9 to 12 items each. Items for different scales are interspersed throughout the inventory. The 75 CCTDI statements express familiar beliefs, expectations, opinions, perceptions, and values. For example, the statement "It's never easy to decide between competing points of view" assesses one's disposition toward truth seeking, and the statement "Considering all the alternatives is a luxury I can't afford" measures one's inclination toward open-mindedness. (For sample items of all seven scales, see Appendix B.)

For each statement. the participants rated themselves on a 6-point Likerttype scale ranging from strongly disagree (1) to strongly agree (6), with 1 indicating a strong disagreement with the statement and 6 denoting that they agree with the statement. There is no neutral option. Moreover, for each statement, to agree is consonant with the critical thinking disposition assessed, whereas to disagree is in opposition to the critical thinking disposition assessed. As reported in 
the CCTDI manual, the inventory is available in a number of languages, including English, Spanish, French, Japanese, and Hebrew. In the present study, the participants completed a Chinese version of the inventory that was translated and back-translated between Chinese and English particularly for this study.

As reported in the CCTDI manual, Cronbach alpha coefficients for the seven scales in the initial CCTDI pilot test ranged from .71 to 80 . Factor analysis supported retention of the items within their respective scales. The manual also reported external validity data for the inventory. The CCTDI bas been studied with such constructs as openness to experience, ego resiliency, motivation, and academic achievement (see Facione et al., 2001, for details). In a PsycInfo database search covering the period between the year 1990 and the year 2001, with "critical thinking disposition" as the key words, I found 10 studies that used the CCTDI.

These studies were investigations of the relationships between the critical thinking dispositions and a variety of cognitive and psychological constructs. For example, I found that critical thinking dispositions significantly predicted the academic and clinical performance of nursing students (Bachman, 1999) and students' evaluations of teaching strategies (Ishiyama, McClure, Hart, \& Amico, 1999). Also for instance, Peterson (1996) showed that participants who held the personal epistemological belief that knowledge is constructed or relativistic had stronger dispositions toward critical thinking than did participants who held the personal epistemological belief that knowledge is absolute or concrete. Finally, only 1 of the 10 studies investigated the relationship of critical thinking dispositions to learning styles (Mcdade, 2000), as has been reviewed earlier.

In the present study, the Cronbach alpha coefficients for the Beijing sample were $.68, .59, .60, .56, .75, .61$, and .73 , respectively, for the truth seeking (T), open-mindedness $(\mathrm{O})$, analyticity (A), systematicity (S), CT self-confidence (C), inquisitiveness (I), and the maturity (M) scales. For the Nanjing sample, Cronbach alpha coefficients were $.67, .60, .59, .70, .73, .63$, and .70 for the $\mathrm{T}, \mathrm{O}, \mathrm{A}$, $\mathrm{S}, \mathrm{C}, \mathrm{I}$, and $\mathrm{M}$ scales, respectively. These internal scale reliabilities are, in general, slightly lower than the ones reported in the CCTDI manual. However, given the heterogeneity of the items in each scale and given that this is the first time that the CCTDI was used with Chinese university students, the reliability data were considered adequate for the remaining statistical analyses to be conducted.

Moreover, the validity of the CCTDI was assessed by an exploratory factor analysis of the seven scales. As demonstrated in Table 1, results from the two samples are strikingly similar.

I obtained a two-factor model for both samples. The first factor was dominated by loadings from the T, O, S, and M scales, and the second by loadings from the $\mathrm{A}, \mathrm{C}$, and 1 scales. The two factors in the Beijing sample accounted for $69.7 \%$ of the variance in the data, and the two factors in the Nanjing sample accounted for $61.1 \%$ of the variance in the data. No previous results in the literature are available to compare with the present factor loadings. However, given the great resem- 
TABLE 1. Oblimin-rotated Two-Factor Model for the California Critical Thinking Disposition Inventory

\begin{tabular}{|c|c|c|c|c|c|}
\hline \multirow[b]{2}{*}{ Scale } & \multirow{2}{*}{$=$} & \multicolumn{2}{|c|}{ Beijing $(N=268)$} & \multicolumn{2}{|c|}{ Nanjing $(N=296)$} \\
\hline & & Factor 1 & Factor 2 & Factor 1 & Factor 2 \\
\hline Truth Seeking & & .85 & & .77 & \\
\hline Open-Mindedness & & .53 & 40 & .75 & \\
\hline Analyticity & & .40 & .61 & .36 & .77 \\
\hline Systematicity & & .75 & & .74 & .33 \\
\hline CT Self-Confidence & & & .90 & & .83 \\
\hline Inquisitiveness & & & .85 & 31 & .79 \\
\hline Maturity & & .86 & & .70 & \\
\hline$\%$ of variance & & 48.19 & 21.53 & 38.81 & 22.32 \\
\hline Cumulative \% & & 48.19 & 69.72 & 38.81 & 61.14 \\
\hline Eigenvalue & & 3.37 & 1.51 & 2.72 & 1.56 \\
\hline
\end{tabular}

Note. $\mathrm{CT}=$ critical thinking.

blance between the two sets of results, I am confident in the validity of the CCTDI for assessing Chinese university students' critical thinking dispositions.

\section{Data Analysis}

Previous findings have been mixed regarding the effects of student characteristics (such as age, gender, university class level, and field of study) on both thinking styles (e.g., Sternberg \& Grigorenko, 1995; Zhang, 1999, 2001a, $2001 \mathrm{c}$; Zhang \& Postiglione, 2001; Zhang \& Sachs, 1997) and critical thinking (e.g., Anderson \& Saucier, 1999; Hawley, 1998; Mcdade, 2000; Peterson. 1996; Walsh, 1997). Consequently, I conducted preliminary statistical analyses (using zero-order correlations and multivariate analysis of variance) to identify possible group differences in thinking styles and critical thinking dispositions that were based on age, gender, university class level, and field of study. For both samples, no significant differences were identified in the thinking style scales or in the critical thinking disposition scales based on any of the student characteristics tested.

To test the predictions made about the contributions of thinking styles to critical thinking dispositions, I conducted two exploratory statistical procedures (zero-order correlation matrix and factor analysis) for each sample, followed by a predictive statistical procedure (stepwise multiple-regression analysis). First, I computed a zero-order correlation matrix with the 13 thinking style scales as one set of the variables and the seven critical thinking disposition scales as the other. 
The aim of this analysis was to obtain a general picture of how scales from the two inventories are related to one another.

Second, I submitted all thinking style scales and critical thinking disposition scales to an exploratory factor analysis with an oblique rotation. The underlying assumption for this analysis was that if the thinking style construct and the critical thinking disposition construct are related, high loadings for at least one of the resulting factors should involve scales from both inventories. That is, the scales from the two inventories should share common variance in the data. Finally, I conducted stepwise multiple-regression procedures, with the thinking style scales as independent variables and the critical thinking disposition scales as the dependent variables. The aim of this analysis was to identify the degree and nature of the contributions of thinking styles to the critical thinking dispositions,

\section{Results}

\section{Zero-Order Correlations}

Tables 2 and 3 give Pearson's correlation coefficients among the scales from the two inventories for the Beijing sample and the Nanjing sample, respectively. Again, the two sets of results were almost identical. In general, for both samples, I identified a large number of significantly positive correlations. Neither set of data resulted in significantly negative relationship between any of the two scales across the two inventories. Furthermore, in both data sets, two of the seven critical thinking disposition scales (the Open-Mindedness and Analyticity scales) were positively related to all thinking style scales. In addition, for both samples, the Maturity scale was the one that resulted in the smallest number of significant correlations with thinking styles: five for the Beijing sample and four for the Nanjing sample. Finally, for both samples, three of the thinking styles (local, oligarchic, and anarchic) were positively related to all seven critical thinking dispositions.

These significant relationships lent partial support to the predictions. As predicted, the Type 1 thinking styles manifested significantly positive relationships to critical thinking dispositions. Also, as predicted, Type 3 thinking styles were significantly related to critical thinking dispositions (no prediction was made regarding the direction of the correlations). However, unlike my prediction, not only was there no significant negative relationship between any of the Type 2 thinking styles and any of the critical thinking dispositions, but also there was a significantly positive relationship between Type 2 thinking styles and particular critical thinking dispositions in both data sets.

\section{Factor Analysis}

Exploratory principal-component factor analysis with an oblique rotation yielded five factors with eigenvalues greater than 1 for both samples. Further- 


\begin{abstract}
TABLE 2. Pearson Correlation Coefficients for the Thinking Styles Inventory and the California Critical Thinking Disposition Inventory (Beijing Sample)
\end{abstract}

\begin{tabular}{|c|c|c|c|c|c|c|c|}
\hline Scale & $\mathrm{T}$ & $\mathrm{O}$ & A & S & C & 1 & M \\
\hline Legislative & .12 & $.32^{* * *}$ & $.42 * *$ & .06 & $.50^{16 *}$ & $.50^{\text {*** }}$ & -.03 \\
\hline Executive & $37^{* \cdots *}$ & $33^{* *}$ & $.39^{4 * 3}$ & $31^{* * k}$ & $.19=$ & $17^{\text {串* }}$ & 12 \\
\hline Judicial & $.19 * *$ & $30 *$ & $.45 * *$ & $.13^{*}$ & $.54^{* *}$ & $.46^{*}$ & .09 \\
\hline Global & $.25^{\text {k } 3 k \text { : }}$ & $31 * *$ & $35^{* *}$ & $.17^{*}$ & $36 * 26$ & .28 稌 & 11 \\
\hline Local & $.33^{i k=k}$ & 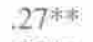 & $35^{\text {番示 }}$ & $.33^{\text {*:* }}$ & $.24 * *$ & $14^{*}$ & .27 米丮 \\
\hline Liberal & $.18 * *$ & .29 井* & $.34 *$ & $.1 \mathrm{I}$ & $.58^{i k 2 k}$ & $.38^{* *}$ & $.18 * *$ \\
\hline Conservative & $.38^{k * k}$ & $.23 * *$ & .29 米 & $32^{* *}$ & -.05 & .02 & $.28^{* * *}$ \\
\hline Hierarchical & .08 & $18^{* * *}$ & $.37 * *$ & .06 & $40^{* *}$ & $39 * *$ & -.02 \\
\hline Monarchic & $.27^{* *}$ & $.29^{3}$ 浱 & $.34 * *$ & $.16^{*}$ & $36^{* * *}$ & $.23 * *$ & .06 \\
\hline Oligarchic & $.45^{* * *}$ & $.43^{* *}$ & $.39 * 13$ & $32^{* *}$ & $.19^{1 k * k}$ & $.20 * *$ & $.15^{\text {i }}$ \\
\hline Anarchic & $.31^{* * *}$ & 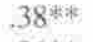 & $.37 * *$ & $.25^{* *}$ & $.43^{* *}$ & $.34^{* *}$ & $.15 *$ \\
\hline Internal & .11 & $26^{423}$ & $30^{\text {k }{ }^{2}}$ & .07 & $36^{* 1: 3}$ & $.37 *$ & .09 \\
\hline External & .11 & $19 * *$ & $.18 * *$ & .08 & $.26 * *$ & $.29^{* k}$ & -.03 \\
\hline
\end{tabular}

Note. $\mathrm{T}=$ Truth Seeking: $\mathrm{O}=\mathrm{Open}-$ Mindedness; $\mathrm{A}=$ Analyticity: $\mathrm{S}=$ Systematicity; $\mathrm{C}=\mathrm{CT}$ Self-Confidence $\mathrm{I}=$ Inquisitiveness: $\mathrm{M}=$ Maturity.

$p<.05 * * p<.01$.

more, the two sets of results resembled each other to a large degree. The five factors accounted for $67 \%$ of the variance in the Beijing data and $61 \%$ of the variance in the Nanjing data. For both samples, the variance for two of the five factors was shared by scales from both inventories, suggesting significant overlap between thinking styles and critical thinking dispositions. For both samples, Factor 1 was dominated by positive high loadings of Type 1 and Type 3 thinking styles as well as by two of the critical thinking disposition scales (CT Self-Confidence and Inquisitiveness). Furthermore, the conservative style (a Type 2 thinking style) negatively loaded on the first factor.

Factor 2 in the Beijing data and Factor 3 in the Nanjing data were also similar. Both factors were dominated by high loadings of the oligarchic thinking style (a Type 3 style) and four of the critical thinking disposition scales (Truth Seeking. Open-Mindedness, Systematicity, and Maturity). The analyticity critical thinking disposition scale was split between the first two factors in the Beijing sample. whereas it was split between the first and third factor in the Nanjing sample. Therefore, together, Factors 1 and 2 for the Beijing sample suggested that Type 1 and Type 3 thinking styles were positively related to critical thinking dispositions and that one of the Type 2 thinking styles (the conservative style) was negatively related to critical thinking dispositions, as did Factors 1 and 3 for the Nanjing 


\begin{abstract}
TABLE 3. Pearson Correlation Coefficients for the Thinking Styles Inventory and the California Critical Thinking Disposition Inventory (Nanjing Sample)
\end{abstract}

\begin{tabular}{|c|c|c|c|c|c|c|c|}
\hline Scale & $\mathrm{T}$ & $\mathrm{O}$ & A & S & C & I & M \\
\hline Legislative & .03 & $.12^{k=}$ & $.23^{* * *}$ & .08 & $.34 * *$ & $.19 * *$ & -.03 \\
\hline Executive & $.27^{* *}$ & $.26^{* *}$ & $.34 \%$ & $.27 * *$ & $18^{* *}$ & $.12^{*}$ & .08 \\
\hline Judicial & $.20^{k *}$ & $20^{\text {ikati }}$ & $34^{* * 1 *}$ & $.13^{*}$ & $46^{\text {titiks }}$ & $.36^{\text {thal }}$ & -.09 \\
\hline Global & $16 * *$ & $.21 * *$ & $.14 *$ & .20 का & $17^{* *}$ & $.20^{* * *}$ & .08 \\
\hline Local & $.23^{\text {하 }}$ & $26^{* 13}$ & $.23^{\text {*:* } *}$ & $.12^{*}$ & $.21^{*} * 3$ & .18 k야 & $.20^{* * *}$ \\
\hline Liberal & $.13^{*}$ & $.25^{* *}$ & $.24 * *$ & .04 & $.55^{* * \pi}$ & $.36^{k \text { ko }}$ & -.08 \\
\hline Conservative & $30^{\text {*** }}$ & $.35^{* * 4}$ & $.20^{* *}$ & $.27 * *$ & -.07 & .02 & $.23^{* * *}$ \\
\hline Hierarchical & -.04 & $.17 * \%$ & $.19 * *$ & -01 & $.37^{2 * * 3}$ & $.13^{*}$ & -.10 \\
\hline Monarchic & .37 *ik & $.15^{*}$ & $28^{* * *}$ & $.23^{* *}$ & $.26 * *$ & $.24 *$ & .08 \\
\hline Oligarchic & $35 * *$ & $.31 * *$ & $.23 * *$ & $.22^{\text {*⿻丷木 }}$ & 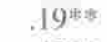 & $.15^{\text {kis }}$ & $.22^{* 3 *}$ \\
\hline Anarchic & $.31 * *$ & $.38 \%$ & $.37 * *$ & $.25 *$ & $.43 * \%$ & $34^{* * *}$ & $.15^{*}$ \\
\hline Internal & 03 & $24 * *$ & $.12^{*}$ & .10 & $31^{* * *}$ & $.23^{* * 4}$ & .04 \\
\hline External & -.02 & $.23^{* * *}$ & $.18^{* * *}$ & .04 & $.24^{* *}$ & $.20^{* * *}$ & -08 \\
\hline
\end{tabular}

Note: $\mathrm{T}=$ Truth Seeking; $\mathrm{O}=$ Open-Mindedness; $\mathrm{A}=$ Analyticity: $\mathrm{S}=$ Systematicity; $\mathrm{C}=\mathrm{CT}$ Self-Confidence; $\mathbf{I}=$ Inquisitiveness; $M=$ Maturity.

$* p<.05,{ }^{* *} p<.01$.

sample. The first two factors explained $46 \%$ of the variance in the Beijing data, and the first and third factors together accounted for $31 \%$ in the Nanjing data.

The remaining three factors (Factors 3,4 , and 5 for the Beijing data, and Factors 2,4 , and 5 for the Nanjing data) were dominated by high loadings of scales from either the TSI or the CCTDI. First, Factor 3 of the Beijing data and Factor 2 of the Nanjing data were both dominated by high loadings of Type 2 thinking styles, including the executive, conservative, and monarchic thinking styles. Second, Factor 4 (for both samples) was dominated by high loadings of a contrasting pair of Type 3 styles: the internal and external thinking styles. Finally, Factor 5 (for both samples) captured high loadings of a second contrasting pair of thinking styles: the global style (one of Type 1 styles) and the local style (one of Type 2 styles; see Tables 4 and 5 for the detailed results of these factor analyses).

For both samples, factor loadings in two of the five factors provided strong, although not complete, support to the predictions. As predicted, what was revealed by the first two factors of the Beijing sample (and by the first and third factors of the Nanjing sample) were positive relationships of the disposition scales to particular thinking styles of both Type 1 and Type 3. Furthermore, as predicted, the first factor (for both samples) revealed a negative relationship between disposition scales and the Type 2 conservative thinking style. 


\section{TABLE 4. Factor Loadings for the Thinking Style Inventory (TSI) and the California Critical Thinking Disposition Inventory (CCTDI) (Beijing Sample)}

\begin{tabular}{|c|c|c|c|c|c|}
\hline Scale & Factor 1 & Factor 2 & Factor 3 & Factor 4 & Factor 5 \\
\hline \multicolumn{6}{|l|}{ TSI } \\
\hline Legislative & .74 & & & & \\
\hline Executive & & & .84 & & \\
\hline Judicial & .78 & & & & \\
\hline Global & & & & & -.61 \\
\hline Local & & & & & .77 \\
\hline Liberal & .84 & & & & \\
\hline Conservative & -.33 & & .73 & & .32 \\
\hline Hierarchical & .46 & & .35 & & $x^{2}$ \\
\hline Monarchic & & & .65 & & \\
\hline Oligarchic & & .47 & .41 & & \\
\hline Anarchic & .65 & & & & .41 \\
\hline Internal & .51 & & & -.67 & \\
\hline External & .37 & & & .83 & \\
\hline \multicolumn{6}{|l|}{ CCTDI } \\
\hline $\mathrm{T}$ & & .82 & & & \\
\hline $\mathrm{O}$ & & .72 & & & \\
\hline A & 46 & .44 & & & \\
\hline$S$ & & .79 & & & \\
\hline C & .78 & & & & \\
\hline I & .70 & & & & \\
\hline M & & .77 & & & \\
\hline \% of variance & 30.01 & 15.50 & 7.96 & 7.00 & 6.32 \\
\hline \multicolumn{6}{|l|}{ Cumulative } \\
\hline variance & 30.01 & 45.51 & 53.47 & 60.47 & 66.79 \\
\hline Eigenvalue & 6.00 & 3.10 & 1.59 & 1.40 & 1.26 \\
\hline
\end{tabular}

Note, Factor loadings below $10.30 \mathrm{r}$ have been omitted. $\mathrm{T}=$ Truth Seeking; $\mathrm{O}=\mathrm{Open-Mind-}$ edness: $\mathrm{A}=$ Analyticity; $\mathrm{S}=$ Systematicity; $\mathrm{C}=\mathrm{CT}$ Self-Confidence; $\mathrm{I}=$ Inquisitiveness; $\mathrm{M}=$ Maturity.

\section{Multiple Regressions}

Results from multiple-regression procedures for both samples indicated that all seven critical thinking disposition seales were significantly predicted by particular thinking styles. Although the statistically significant predictors of each of the seven critical thinking dispositions were not always exactly the same thinking styles, the general trends of predictions for the two samples were largely consistent. First, for both samples, 11 of the 13 thinking styles entered the regression 
TABLE 5. Factor Loadings for the Thinking Style Inventory (TSI) and the California Critical Thinking Disposition Inventory (CCTDI) (Nanjing Sample)

\begin{tabular}{|c|c|c|c|c|c|}
\hline Scale & Factor 1 & Factor 2 & Factor 3 & Factor 4 & Factor 5 \\
\hline \multicolumn{6}{|l|}{ TSI } \\
\hline Legislative & .64 & & & .44 & \\
\hline Executive & & .85 & & & \\
\hline Judicial & .70 & & & & \\
\hline Global & & .32 & & & -.78 \\
\hline Local & 30 & 30 & & & .76 \\
\hline Liberal & .79 & & & & \\
\hline Conservative & -.31 & .80 & & & \\
\hline Hierarchical & 31 & .47 & & & \\
\hline Monarchic & & .51 & & & \\
\hline Oligarchic & & .40 & .56 & & \\
\hline Anarchic & .52 & .30 & & & \\
\hline Internal & & & & .82 & \\
\hline External & .52 & & & -.75 & \\
\hline \multicolumn{6}{|l|}{ CCTDI } \\
\hline $\mathrm{T}$ & & & .73 & & \\
\hline O & & & .73 & & \\
\hline A & .50 & & 45 & & \\
\hline $\mathrm{S}$ & & & .70 & & \\
\hline C & .77 & & & & \\
\hline I & 66 & & .34 & & \\
\hline M & & & .67 & & \\
\hline$\%$ of variance & 21.90 & 16.34 & 9.19 & 7.14 & 6.21 \\
\hline \multicolumn{6}{|l|}{ Cumulative } \\
\hline variance & 21.90 & 38.24 & 47.42 & 54.56 & 60.78 \\
\hline Eigenvalue & 4.38 & 3.27 & 1.84 & 1.43 & 1.24 \\
\hline
\end{tabular}

Note. Factor loadings below $10.30 \mathrm{l}$ have been omitted. $\mathrm{T}=$ Truth Seeking: $\mathrm{O}=$ Open-Mindedness: $\mathrm{A}=$ Analyticity: $\mathrm{S}=$ Systematicity; $\mathrm{C}=\mathrm{CT}$ Self-Confidence; $\mathrm{I}=$ Inquisitiveness: $\mathrm{M}=$ Maturity.

model for at least one critical thinking disposition scale. The two styles that did not result in any significant prediction for any disposition scale in both sets of data were the executive and the monarchic thinking styles.

The degree to which thinking styles significantly predicted critical thinking dispositions was manifested through the multiple $R$ values that ranged from .17 (for Maturity) to .50 (for CT Self-Confidence) with a median of .38 (for Truth Seeking) for the Beijing sample, and from .13 (for Maturity) to .46 (for CT SelfConfidence) with a median of .23 (for Open-Mindedness) for the Nanjing sam- 
ple. For both samples, all significant beta weights were positive, denoting a positive contribution of the thinking styles to the critical thinking dispositions (see Tables 6 and 7 for detailed statistics obtained from these multiple-regression procedures for the Beijing and the Nanjing samples, respectively).

These results from the multiple-regression analyses also lent fairly strong support to the predictions. Again, as predicted, Type 1 thinking styles significantly predicted stronger dispositions toward critical thinking. Furthermore, results also indicated that Type 3 thinking styles significantly predicted a stronger inclination toward critical thinking as well. However, for both samples. two of the Type 2 thinking styles (conservative and local) unexpectedly contributed significantly to the variance in particular critical thinking dispositions in a positive way.

\section{Discussion}

In the present study I examined the statistical contributions of thinking styles to critical thinking dispositions. The hypothesized relationships were tested in two samples of Chinese university students by these statistical procedures. Results from the three statistical procedures have provided largely consistent findings, but with certain conflicts. Because almost identical findings were obtained from the two samples, the following discussion will be made in reference to findings from both samples unless specified otherwise.

Regarding the consistent findings, results from all three procedures indicated significant positive relationships of critical thinking dispositions to both Type 1 and Type 3 thinking styles, Of course, in the case of multiple-regression analyses, results would indicate a predictive relationship. That is, Type 1 and Type 3 thinking styles statistically predicted variations in critical thinking dispositions.

Regarding the conflicting findings, whereas results from both the zero-order correlations and the multiple-regression procedures revealed a positive relationship between the conservative thinking style and particular critical thinking dispositions, results from the factor analysis suggested a negative relationship between the two. The former finding was not consistent with the earlier prediction about the relationship between Type 2 thinking styles and critical thinking dispositions, whereas the latter confirmed the earlier prediction.

Furthermore, apart from the conservative thinking style, another Type 2 thinking style - the local thinking style - also resulted in significant positive relationships with several critical thinking disposition scales. This finding, as mentioned earlier, is also in direct opposition to the prediction.

Given these almost identical findings from two sets of data, what explains the extent to which the findings of this study make substantive sense? Furthermore, these findings make it necessary to examine more closely the nature of the critical thinking disposition construct and to explain why some findings are contradictory to our earlier predictions. 
What substantive sense is made by the findings that supported the earlier predictions? In general, the findings make a great deal of substantive sense. Take the significant prediction of particular thinking styles for CT Self-Confidence, for example. Across the two samples, the following thinking styles significantly predicted CT Self-Confidence: the legislative, liberal, judicial, anarchic, hierarchical, and global thinking styles. Persons with CT self-confidence are characterized by trusting themselves to make good judgments (Facione et al., 2001). Each of the aforementioned thinking styles would contribute to people's CT selfconfidence in the following manner.

First, the legislative, liberal, and anarchic thinking styles would enable people to do things in a creative (legislative), nontraditional (liberal style), and flexible (anarchic) way. Being creative, nontraditional, and flexible is clearly a manifestation of self-confidence. Second, being constantly engaged in evaluating (judicial style) and prioritizing (hierarchical) one's own or other people's work would be necessary steps for making good judgments. Finally, to make good judgments, one has to evaluate the different aspects of an issue in relation to the holistic picture (global style) under consideration. Therefore, the significant relationships of CT self-confidence to these styles seem to make complete substantive sense.

A second example is the significant prediction of the legislative, judicial, hierarchical, external, and internal thinking styles (across the two samples) for the inquisitiveness disposition. Inquisitive individuals are characterized by their curiosity for learning how things work and by their desire for being well informed. Being inquisitive, however, would need the aforementioned thinking styles. For example, to be inquisitive, an individual needs to prioritize (hierarchical style) and decide what information he or she needs. After deciding the particular information one wants, the individual needs to analyze (judicial style) and understand the information. To have a thorough understanding of the information, the inquisitive person would need to investigate the issue by both working alone (internal style) and consulting other people (external style). Consequently, the significant relationships of the inquisitive disposition to the thinking styles just mentioned also make substantive sense.

Finally, we discuss the significant relationships of the analyticity disposition to the judicial, oligarchic, conservative, global, local, hierarchical, and liberal thinking styles across the two samples. Analytically inclined people are characterized by their alertness to potential difficulties and by their persistence in engaging in reasoned inquiry that is aimed at problem solving. In a similar vein, characteristics identified in analytically inclined people also can be easily identified in people who tend to use judicial, oligarchic, global, local, hierarchical, and liberal thinking styles. People with the judicial thinking style tend to be engaged in evaluative and analytical types of tasks. To make a well-reasoned inquiry, one has to compare and contrast among many different aspects (requiring oligarchic style) of an issue, take new perspectives in examining an issue (liberal), and set logical orders (requiring hierarchical style) for the different aspects of the issue. More- 
TABLE 6. Contributions of Thinking Styles to Critical Thinking Dispositions: $R^{2} \mathrm{~s}, \beta \mathrm{s}$, and $F \mathrm{~s}$ (Beijing Sample)

$\begin{array}{llll}\text { CTD scale } & \mathrm{T} & \mathrm{O} & \mathrm{A}\end{array}$

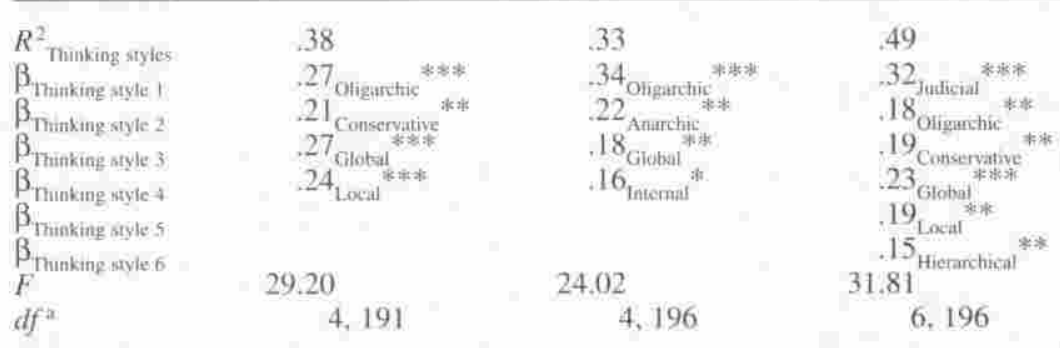

Note. ${ }^{2}$ Listwise cases exclusion was used. $\mathrm{T}=$ Truth Seeking; $\mathrm{O}=$ Open-Mindedness; $\mathrm{A}=$ Analyticity: $\mathrm{S}=$ Systematicity; $\mathrm{C}=\mathrm{CT}$ Self-Confidence $\mathrm{I}=$ Inquisitiveness; $\mathrm{M}=$ Maturity. ${ }^{*} p<.05, * * p<.01$. ${ }^{* * * *} p<.001$.

TABLE 7. Contributions of Thinking Styles to Critical Thinking Dispositions: $R^{2} \mathrm{~s}, \beta \mathrm{s}$, and $F \mathrm{~s}$ (Nanjing Sample)

\begin{tabular}{llll}
\hline \hline CTD scale & T & O & A
\end{tabular}

$R^{2}$
$\beta_{\text {Thinking styles }}$
$\beta_{\text {Thinking style I }}$
$\beta_{\text {Thinking styte 2 }}$
$\beta_{\text {Thinking style } 3}$
$\beta_{\text {Thinking syle 4 }}$
$F$
$d f^{u}$

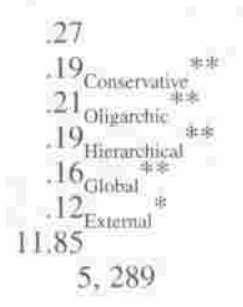

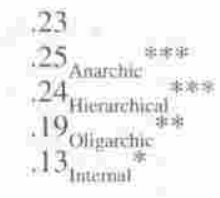

18.37

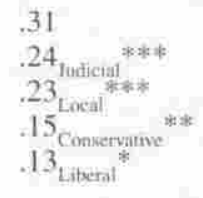

19.69

4. 290

4, 290

Note. "Listwise cases exclusion was used, $\mathrm{T}=$ Truth Seeking; $\mathrm{O}=$ Open-Mindedness; $\mathrm{A}=$ Analyticity; $\mathrm{S}=$ Systematicity; $\mathrm{C}=\mathrm{CT}$ Self-Confidence; $\mathrm{I}=$ Inquisitiveness; $\mathrm{M}=$ Maturity. ${ }^{*} p<.05 . * 4 p<.01 .{ }^{* * * *} p<.001$. 


\section{S}

C

I

M

\begin{tabular}{|c|}
\hline 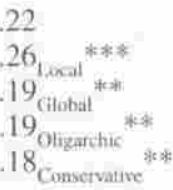 \\
\hline
\end{tabular}

14.04

\begin{tabular}{|c|}
\hline $\begin{array}{l}50 \\
31_{\text {Liberal }} \\
.23_{\text {judicial }} \\
.18\end{array}$ \\
\hline
\end{tabular}

39.49

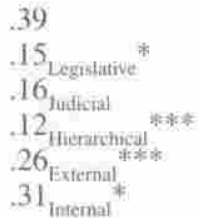

24.29

\begin{abstract}
5, 196
\end{abstract}
5,194

10.05

\section{.17}

.20 ***

25 Consenative *ks

.29 Litierai

17 Lequithative kok:

4, 194
S

.18

.22 Losal *ink

19 Consicrative *as

$.15_{\text {Hierarehioal }}$

$.14_{\text {Global }}$ *

11.11
C

I

M

.13

.27 Conservative **

26 oligatitiva*

17 Orgarchice

24 Extorib

.14 Lacal

8.58

\section{289}


over, a well-reasoned solution to a problem also requires an individual to take into account the global picture of an issue (global style) as well as to deal with the specific aspects of the issue (local style). Thus, it is reasonable to state that the significant relationships of the analyticity disposition to the judicial, oligarchic, global, local, and hierarchical thinking styles make substantive sense.

Notice, however, that two relationships discussed in the final example are unexpected. The first is the significant relationship between the analyticity disposition and the local thinking style - a Type 2 thinking style. Although this finding was contradictory to the general prediction regarding the relationships between Type 2 thinking styles and critical thinking dispositions, a post-hoc explanation is plausible. As has just been discussed, the local thinking style may be required to complement the global thinking style in contributing to the prediction of the analyticity disposition.

Recall that Type 1 thinking styles are characterized by their requirements of higher levels of cognitive complexity and Type 2 styles by their requirements of lower levels of cognitive complexity. Also recall that the global thinking style has been categorized as a Type 1 style and that the local thinking style has been classified as a Type 2 style. In this context, however, the global thinking style did not exhibit superiority to the local thinking style in terms of the level of cognitive complexity it requires. As a matter of fact, the local thinking style has positively contributed to the prediction of more than just the analyticity disposition. The local style also has positively contributed to the prediction of two other critical thinking dispositions (systematicity and maturity) for both samples and to the prediction of an additional critical thinking disposition (truth seeking) for the Beijing sample.

The second unexpected significant relationship is that between the analyticity disposition and the conservative style. The conservative style is, in fact, the thinking style that has led to the conflicting findings in this study. On the one hand, the zero-order correlations and the multiple-regression procedures revealed positive relationships of the conservative thinking styles to three of the disposition scales (Truth Seeking, Analyticity, and Maturity) for both samples and to two additional disposition scales (Open-Mindedness and Systematicity) for the Nanjing sample. On the other hand, for both samples, results from factor analysis showed negative relationships of the conservative thinking style to three of the dispositions, including analyticity, CT self-confidence, and inquisitiveness. Thus, results from the former two statistical procedures (zero-order correlation and multiple regression) and the latter one (factor analysis) have created an inconsistency.

How should this inconsistency be taken? A careful cross-examination of the data from all three statistical procedures indicated that it is more likely that the conservative style had a positive, rather than a negative, relationship with analyticity because the negative factor loading for the conservative style in the first factor (in both samples) was almost negligible. That is, the factor loading of .33 for the Beijing sample and that of .31 for the Nanjing sample were merely above the cutoff score for suppression. On the contrary, the positive relationship revealed 
by both the zero-order correlation and the multiple-regression procedures are hard to be ignored as they are both significant at the .01 level-a stringent level of statistical significance. Thus, it is believed that the conservative style is more likely to have contributed to analyticity positively rather than negatively. Furthermore, like the local style, the conservative style was also positively related to three additional dimensions of critical thinking dispositions (truth seeking, systematicity, and maturity) for both samples, as identified by both zero-order correlations and multiple regressions.

The question then arises of why the local and conservative styles contributed positively rather than negatively (as predicted earlier) to some of the seven critical thinking dispositions. To answer this question, I re-examined the basis on which the earlier predictions about the relationships between thinking styles and critical thinking dispositions were made as well as the nature of the critical thinking disposition construct. The predictions were based on previous findings on the relationships of thinking styles to other constructs examined such as learning approach, self-esteem, and cognitive development, as well as on the perception that critical thinking disposition is a positive human attribute.

However, a comparison between the nature of the critical thinking disposition construct and that of the other constructs (i.e., learning approach, self-esteem, and cognitive development) indicated that critical thinking disposition is different from the other constructs in a fundamental way. That is, whereas the critical thinking disposition has seven dimensions, the previously examined variables are all one-dimensional with two dichotomous terms such as the deep approach versus the surface approach, high self-esteem versus low self-esteem, and a high cognitive-developmental level versus a low cognitive-developmental level. Therefore. it seems that it was not appropriate to have made the predictions about the relationships between thinking styles and critical thinking dispositions merely on the basis of previous findings. Consideration should have been given to the nature of the construct (i.e., the critical thinking disposition) that was examined.

As has been mentioned earlier, each of the seven critical thinking dispositions has its own definition and its own characteristics. Although all critical thinking dispositions could be perceived as positive attributes, they could also be very different from one another. For example, the open-mindedness dimension describes a very different critical thinking disposition than does the systematicity dimension. Whereas open-minded individuals are characterized by their divergent or creative thinking, systematic individuals are known for their tendency for focusing on concrete or specific issues. Obviously, open-mindedness and Type 1 thinking styles (especially the legislative and liberal styles) share a major common characteristic - that of generating creativity. By the same token, the nature of systematicity is consistent with that of Type 2 thinking styles, especially the local style (both being concrete, detailed, and specific).

Indeed, a closer look at the semantics used in the definition of "an ideal critical thinker" as stated in The Delphi Report revealed that Type 2 thinking styles, 
especially the conservative and local styles, should contribute to critical thinking dispositions, especially to the analyticity, truth seeking, systematicity, and maturity dimensions, as has been demonstrated by the present results. For instance, in defining the ideal critical thinker, the report used such words as prudent, focused, and precise. Whereas a prudent individual can be conservative in thinking style, a focused individual seeking precise information can be local in thinking style.

Therefore, this re-examination of the foundation of the earlier predictions and of the nature of critical thinking dispositions has facilitated an understanding of the present findings. Thus, like Type 1 and Type 3 thinking styles. Type 2 thinking styles can also contribute to critical thinking dispositions. Indeed, this finding makes substantive sense. It is easily conceivable that a critical thinker be adept at using a wide range of thinking styles, switching from one to another, depending on the individual's judgment of the thinking styles required by specific situations.

\section{Conclusions and Implications}

The results of the present study have made three contributions. First, in this study I pioneered the employment of the CCTDI among two samples of Chinese university students from mainland China. This is significant not only because the inventory has gained additional psychometric data in a cross-cultural setting but also because it has provided an additional tool to scholars who are interested in examining the critical thinking dispositions of Chinese university students. Until today, no published inventory for assessing Chinese university students ${ }^{*}$ critical thinking dispositions has been identified in the literature. Thus, it is reasonable to claim that the CCTDI has great potential for being used in future studies of the critical thinking dispositions among Chinese university students.

Second, this study further explored the nature of thinking styles as defined in the theory of mental self-government. In this study, the term Type 3 thinking styles was coined to refer to thinking styles that can be used to deal with tasks that may require either Type 1 (creativity generating and higher levels of cognitive complexity) or Type 2 (norm-conforming and lower levels of cognitive complexity) thinking styles. Furthermore, this study indicated that among the four Type 2 thinking styles previously defined, the executive and monarchic thinking styles could be very different from the local and conservative thinking styles. The former did not contribute to the prediction of any critical thinking disposition, whereas each of the latter two contributed to the prediction of four of the seven critical thinking dispositions. These different findings regarding the former two styles and the latter two styles imply that being simple-minded (as in the case of using executive and monarchic thinking styles) and being conforming and detail oriented (as manifested in using the conservative and local styles) could be fundamentally different.

Third, this study examined the contributions of thinking styles to the seven critical thinking dispositions defined in the 1990 Delphi Report. Findings showed 
that thinking styles contributed positively to all seven critical thinking dispositions. This significant relationship between the thinking style construct and the critical thinking disposition construct supported the findings in some of the existing studies that examined the relationship between intellectual styles and critical thinking in general (e.g., Bostic, 1989; Gadzella \& Masten, 1998; Marra, 1997). In particular, the present findings supported Mcdade's (2000) study that identified a significant positive correlation between the intuition thinking learning style and the total critical thinking disposition score as measured by the CCTDI.

Thus, the results of the present study contribute to the literature on the relationship between intellectual styles and critical thinking and to the growing body of knowledge on the nature of thinking styles as defined in the theory of mental self-government as well as on the nature of critical thinking dispositions. In particular, the present findings indicated that the multi-dimensionality of the critical thinking disposition construct must be taken into account in the study of its relationships to other variables, including thinking styles.

The importance of the finding about the relationships between thinking styles and critical thinking dispositions lies not only in its contribution to the literature but also in its significant implications for education at the level of instruction and assessment as well as at the level of curriculum development and nonacademic program development. Because thinking styles contribute to critical thinking dispositions, teaching that takes thinking styles into full account can lead to the development of critical thinking dispositions.

At the instruction and assessment level, if teachers' goals are to cultivate students' critical thinking dispositions, they should instruct and assess in ways that both allow students to use their predominant thinking styles and challenge students to develop styles that they normally would not use. For example, teachers could instruct students by using a variety of teaching methods (e.g., lecturing, cooperative learning, problem-based learning, debating, and so forth) so that students with different thinking styles could benefit from their instruction. Likewise, teachers could assess students' academic achievement in as many formats (e.g., multiple-choice test, individual project, reading portfolio, and so forth) as possible so that students with different thinking styles could make the best use of their principal thinking styles. Meanwhile, students could also get the opportunities to develop the thinking styles that they tend to use less frequently.

At the level of curriculum development, if cultivating critical thinking dispositions is one of the objectives of education, which it certainly is, thinking styles should also be taken into consideration in the process of designing an academic curriculum. A good academic curriculum should be composed of various wellintegrated components, each focusing on the cultivation of particular stylistic dimensions of students, depending on the particular critical thinking dispositions that a particular academic subject is supposed to develop. For example, if enhancing the inquisitiveness disposition is the goal of an academic subject, teaching and learning for that subject should be conducted in ways that would involve frequent 
use of such thinking styles as the legislative, judicial, hierarchical, and external styles, as suggested by results from both samples in the present study.

Furthermore, because both thinking styles and critical thinking dispositions are broad constructs, the implications of the contributions of thinking styles to critical thinking dispositions can be generalized to nonacademic program development. For example, thinking styles can be very useful for short-term or longterm programs that are targeted at developing a specific dimension of critical thinking disposition among students. For example, if the aim of a 2-day career development workshop is to develop students' CT self-confidence, the use and development of such thinking styles as the liberal, judicial, hierarchical, and the global thinking styles (as suggested by the results from both samples) should be deliberately built into the whole process of the workshop.

The results of the present study support existing studies that have shown significant relationships between intellectual styles and critical thinking (e.g., Bostic, 1989; Gadzella \& Masten, 1998; Marra, 1997; Mcdade, 2000). These results provide further evidence for the important role of thinking styles in student learning and development. In the past, the thinking styles as defined in the theory of mental self-government have contributed to a number of dimensions of student learning and development both in and outside the classroom (see Zhang's works as reviewed earlier). In the present study I have identified the importance of thinking styles in yet another dimension of student learning and development: critical thinking dispositions. Thus, results from the present study provide an additional reason for educators to take thinking styles into account in their teaching practice. Educators must respond to students' individual differences in their intellectual styles and create opportunities for students to capitalize on their strengths and compensate for their weaknesses.

\section{REFERENCES}

Anderson, S.. \& Saucier, B. L. (1999). The critical thinking skills of faculty in baccalaureate and masters in nursing programs. Korean Journal of Thinking and Problem Solving. $9(2), 51-62$.

Bachman, M. L. (1999). Anxiety, critical thinking and age as performance predictors of community college nursing students. Dissertation Abstracts International: The Sciences and Engineering, 60 (3B), 1026.

Bernardo, A. B., Zhang, L. F., \& Callueng, C, M. (2002). Thinking styles and academic achievement among Filipino students. The Joumal of Genetic Psychology, 163, $149-163$.

Biggs, J. B. (1978). Individual and group differences in study processes. British Journal of Educational Psychology, 48, 266-279.

Biggs, 1. B. (1992). Why and how do Hong Kong students learn? Using the Learning and Study Process Questionnaires. Education Paper No. 14. Faculty of Education, The University of Hong Kong.

Bostic, J. Q. (1989). Cognitive styles: Their consolidation and relationship, beyond cognitive developmental level and critical thinking ability, to understanding science. Dissertation Abstracts International: Humanities and Social Sciences, 49 (11A), 3320. 
Chickering, A. (1969). Education and identity. San Francisco: Jossey-Bass.

Chickering, A., \& Reisser, L. (1993). Education and identity (2nd ed.). San Francisco: Jossey-Bass.

Coopersmith, S. (1981). Self-esteem inventories. Palo Alto, CA: Consulting Psychologists Press.

Costa, P. T. Jr., \& McCrae, R. R. (1992). The NEO-PI-R; Professional manual, Odessa, FL: Psychological Assessment Resources.

Curry, L. (1983). An organization of leaming styles theory and constructs. ERIC Document $235,185$.

Dai, D. Y., \& Feldhusen, J. F. (1999). A validation of the Thinking Styles Inventory: Implications for gifted education. Roeper Review, 21(4), 302-307.

Entwistle, N. (1981). Styles of teaching and learning: An integrated outline of educational psychology for students, teachers, and lecturers. New York: John Wiley.

Facione, P., \& Facione, N. (1992). CCTDI: A disposition inventory: Millbrae, CA: The California Academic Press.

Facione, P.. Facione, N.. \& Giancarlo, C. (2001). California Critical Thinking Disposition Inventory-Inventory manual. Millbrae, CA: The California Academic Press.

Feldhusen, J. F., \& Goh, B. E. (1995). Assessing and accessing creativity: An integrative review of theory, research, and development. Creativity Research Journal, 8, 231-247.

Gadzella, B. M. \& Masten, W. G. (1998). Relation between measures of critical thinking and learning styles. Psychological Reports, 83(3, Pt. 2), 1248-1250,

Gregore, A. F. (1979). Learning/teaching styles: Potent forces behind them. Educational Leadership, 36, 234-236.

Hawley, D.A. (1998). The measurement of a critical thinking disposition among practicing registered nurses. Dissertation Abstracts International: Humanities and Social Sciences, 59 (4A), 1042.

Holland, J. L. (1973), Making vocational choices: A theory of careers. Englewood Cliffs, NJ: Prentice-Hall.

Holland. J. L. (1994). Self-directed search. Odessa, FL: Psychological Assessment Resources.

Ishiyama, J. T., McClure, M., Hart, H., \& Amico, J. (1999), Critical thinking disposition and locus of control as predictors of evaluations of teaching strategies. College Student Journal, 33, 269-277.

Jones, A. E. (1997). Reflection-impulsivity and wholist-analytic: Two fledglings? Or is R-I a cuckoo? Educational Psychology: 17 (1 \& 2), 65-77.

Jung, C. (1923). Psychological types. New York: Harcourt Brace.

Kagan, J. (1976). Commentary on reflective and impulsive children: Strategies of information processing underlying differences in problem solving. Monographs of the Society for Research in Child Development, 41, No. 5 (Serial No. 168).

Kolb, D. A. (1976). The Learning Style Inventory: Technical manual. Boston: McBer.

Krank, H. M. (1994). Do cognitive styles and learning environment predict critical thinking performance for pre-service teachers? Dissertation Ahstracts International: Humanities and Social Sciences, 54 (9A), 3379.

Lefton, L. A. (1997). Why I teach the way I do: Repackaging psychology. In R. J. Sternberg (Ed.), Teaching introductory psychology: Survival tips from the experts (pp. 65-71). Washington, DC: American Psychological Association.

Marra, S. E. (1997). An exploration of critical thinking, learning style, locus of control, and environmental perception in baccalaureate nursing students. Dissertation Abstracts International: The Sciences and Engineering, 58 (3B), 1215.

Marton, F. (1976). What does it take to learn? Some implications on an alternative view of learning. In N. J. Entwistle (Ed,). Strategies for research and development in higher 
education (pp. 200-222). Amsterdam: Swets and Zeitlenger.

Mccrink, C. L. S. (1999). The role of innovative teaching methodology and learning styles on critical thinking. Dissertation Abstracts International: Humanities and Social Sciences, $59(9 \mathrm{~A}), 3420$.

Mcdade, D. C. (2000). Relationships between learning styles and critical thinking ability among health professional students. Dissertation Abstracts Intemational: Humanities and Social Sciences, 61 (6A), 2212.

Miller, A. (1987). Cognitive styles: An integrated model. Educational Psychology, 7. $251-268$.

Myers, I. B., \& McCaulley, M. H. (1988). Manual: A guide to the development and use of the Myers-Briggs Type Indicator. Palo Alto, CA: Consulting Psychologists Press.

Nathan. Y. H. (1997). Critical thinking: Impact on two classes of nursing students in an academic year. Dissertation Abstracts International: Humanities and Social Sciences, $58(5 \mathrm{~A}), 1614$.

Perry, W. G. (1970). Forms of intellectual and ethical development in the college years: A scheme (2nd ed.). New York: Holt, Rinehart and Winston.

Perry, W. G. (1981). Cognitive and ethical growth: The making of meaning. In A. Chickering (Ed.), The modern American college (pp. 76-116). San Francisco: Jossey-Bass.

Perry, W. G. (1999). Forms of intellectual and ethical development in the college vears: A scheme ( $3 \mathrm{rd}$ ed.). San Francisco: Jossey-Bass.

Peterson, A. K. (1996), The relationship between personal epistemology and accountability on critical thinking disposition. Dissertation Abstracts International: Humanities and Social Sciences, 56 (7A), 2581.

Renzulli, J. S., \& Smith, L. H. (1978). Learning Sryles Inventory. Mansfield Center, CT: Creative Leaming Press.

Riding, R., \& Cheema, I. (I99I). Cognitive styles-An overview and integration. Educational Psychology, II(3\& 4), 193-215.

Schmeck, R. R. (1983). Learning style of college students. In R. F. Dillon \& R. R. Schmeck (Eds.), Individual differences in cognition (Vol. 1, pp. 233-279). San Diego, CA: Acadernic Press.

Sternberg, R. J. (1988). Mental self-government: A theory of intellectual styles and their development. Human Development, 31, 197-224.

Sternberg, R. J. (1997). Thinking styles. New York: Cambridge University Press.

Sternberg, R. J., \& Grigorenko, E. L. (1995). Styles of thinking in the school. European Journal for High Ability, 6, 201-219.

Sternberg, R. J., \& Wagner, R. K. (1992). Thinking Styles Inventory: (Unpublished test, Yale University).

Torrance, E. P., McCarthy, B., \& Kolesinski, M. T. (1988). Style of learning and thinking. Bensenville, IL: Scholastic Testing Service.

Walsh, C. M. (1997). Critical thinking disposition of university students in practice disciplines (nursing, education, and business) and non-practice disciplines. Dissertation Abstracts International: Humanities and Social Sciences, 57 (10A), 4292.

Watson, G., \& Glaser, E. M. (1980). Watson-Glaser Critical Thinking Appraisal. San Antonio, TX: Psychological Corporation.

Witkin, H. A. (1964), Origins of cognitive style. In C. Sheerer (Ed.), Cognition, theory, research, promise (pp. 172-205). New York: Harper and Row.

Zhang, L. F. (1999). Further cross-cultural validation of the theory of mental self-government. The Journal of Psychology, 133, 165-181.

Zhang, L. F. (2000a). Are thinking styles and personality types related? Educational Psychology, 20, 271-283.

Zhang, L. F. (2000b). Relationship between Thinking Styles Inventory and Study Process 
Questionnaire. Personality and Individual Differences, 29, 841-856.

Zhang, L. F. (2001a). Do styles of thinking matter among Hong Kong secondary school students? Personality and Individual Differences, 31, 289-301.

Zhang, L. F. (2001b). Thinking styles and personality types revisited. Personality and Individual Differences, 31, 883-894.

Zhang, L. E. (2001c). Thinking styles, self-esteem, and extracurricular experiences. International Journal of Psychology; 36(2), 100-107.

Zhang, L. F. (2002a). The role of thinking styles in psychosocial development. Journal of College Student Development, 43, 696-711.

Zhang, L. F. (2002b). Thinking styles and the Big Five Personality traits. Educational Psychology, 22, 17-31.

Zhang, L. F. (2002c). Thinking styles and cognitive development. The Journal of Genetic Psychology, 163, 179-195.

Zhang, L. F. (2002d). Thinking styles and modes of thinking: Implications for education and research. The Journal of Psychology, 136, 245-261.

Zhang, L. F., \& Huang, J. F. (2001). Thinking styles and the five-factor model of personality. European Journal of Personality, 15, 465-476

Zhang, L. F., \& Postiglione, G. A. (2001). Thinking styles, self-esteem, and socioeconomic status. Personality and Individual Differences, 31, 1333-1346.

Zhang. L. F., \& Sachs, J. (1997). Assessing thinking styles in the theory of mental selfgovernment: A Hong Kong validity study. Psychological Reports, 81, 915-928.

Zhang, L. F., \& Sternberg, R. J. (1998). Thinking styles, abilities, and academic achievement among Hong Kong university students, Educational Research Journal, 13, 41-62.

Zhang, L. F., \& Sternberg. R. J. (2000). Are learning approaches and thinking styles related? A study in two Chinese populations. The Journal of Psychology, 134. 469-489.

\section{APPENDIX A}

Thinking Styles in the Theory of Mental Self-Government

Dimension Thinking style Description of style

Function Legislative

Executive

Judicial

Form

Hierarchical

Monarchical

Oligarchic
One prefers to work on tasks that require creative strategies; one prefers to choose one's own activities.

One prefers to work on tasks with clear instructions and structures; one prefers to implement tasks with set guidelines.

One prefers to work on tasks that allow for one's evaluation; one prefers to evaluate and judge the performance of other people.

One prefers to distribute attention to several tasks that are prioritized according to one's valuing of the tasks.

One prefers to work on tasks that allow complete focus on one thing at a time.

One prefers to work on multiple tasks in the service of multiple objectives, without setting priorities. 
APPENDIX A (continued)

Thinking Styles in the Theory of Mental Self-Government

\begin{tabular}{|c|c|c|}
\hline Dimension & Thinking style & Description of style \\
\hline & Anarchic & $\begin{array}{l}\text { One prefers to work on tasks that would allow } \\
\text { flexibility as to what, where, when, and how } \\
\text { one works. }\end{array}$ \\
\hline Level & Global & $\begin{array}{l}\text { One prefers to pay more attention to the overall } \\
\text { picture of an issue and to abstract ideas. }\end{array}$ \\
\hline & Local & $\begin{array}{l}\text { One prefers to work on tasks that require } \\
\text { working with concrete details. }\end{array}$ \\
\hline Scope & Internal & $\begin{array}{l}\text { One prefers to work on tasks that allow one to } \\
\text { work as an independent unit. }\end{array}$ \\
\hline & External & $\begin{array}{l}\text { One prefers to work on tasks that allow for } \\
\text { collaborative ventures with other people. }\end{array}$ \\
\hline Leaning & Liberal & $\begin{array}{l}\text { One prefers to work on tasks that involve } \\
\text { novelty and ambiguity. }\end{array}$ \\
\hline & Conservative & $\begin{array}{l}\text { One prefers to work on tasks that allow one to } \\
\text { adhere to the existing rules and procedures in } \\
\text { performing tasks. }\end{array}$ \\
\hline
\end{tabular}

\section{APPENDIX B \\ Sample Items From the California Critical Thinking Disposition Inventory}

Scale

Item

Truth Seeking

Open-Mindedness

Analyticity

Systematicity

CT Self-Confidence

Inquisitiveness

Maturity
It's never easy to decide between competing points of view,

It concerns me that I might have biases of which I'm not aware. It bothers me when people rely on weak arguments to defend good ideas.

I always focus the question before I attempt to answer it.

I'm proud that I can think with great precision.

Most college courses are uninteresting and not worth taking.

Powerful people determine the right answer. 